\title{
Applied geophysics in karst areas: Sinkhole's subsidence susceptibility in Curvelo, MG, Brazil.
}

Victor Lunardi Toledo ${ }^{1},{ }^{2}$, Maria Silvia Carvalho Barbosa ${ }^{1}$, Julio César Lana ${ }^{3}$, Joney Justo da Silva ${ }^{1}$, Jhonatan Pereira Dornelas Borges ${ }^{1},{ }^{2}$, Julia Ferreira Schiavon ${ }^{1},{ }^{2}$, Luis Gustavo de Souza Rezende ${ }^{1},{ }^{2}$, Vinicius Oliveira Queiroz ${ }^{1}{ }^{2}$, Joney Justo'.

${ }^{1}$ UFOP, ${ }^{2}$ SGA Student Chapter, ${ }^{3} \mathrm{CPRM}$ - Brazil Geological Survey.

Copyright 2021, SBGf - Brazilian Society of Geophysics.

This paper was prepared for presentation during the 17th International Congress of the Brazilian Geophysical Society held in Rio de Janeiro, Brazil, $16-19$ August 2021

Contents of this paper were reviewed by the Technical Committee of the 17th International Congress of the Brazilian Geophysical Society and do not necessarily represent any position of the SBGf, its officers or members. Electronic reproduction or storage of any part of this paper for commercial purposes without the written consent of the Brazilian Geophysical Society is prohibited.

\begin{abstract}
In urban karst environments, land subsidence is a geological hazard often associated with urban damage. In these types of landforms, subsidence occurs naturally and mainly associated with human interventions. It is triggered by the dissolution of the substrate with the subsequent sink of the terrain, forming features commonly called dolines or sinkholes. Located in the central area of the Minas Gerais state, Curvelo's town is situated geologically on the southeastern edge of the São Francisco Craton. In this region, recent sedimentary clusters out cover outcropping proterozoic metasedimentary rocks. The Bambuí group, with metapelitic rocks from the Serra de Santa Helena formation and the carbonate rocks of the Sete Lagoas and Lagoa do Jacare formations, represents the most expressive stratigraphic unit. As a result of this limestone substrate, landforms related to karst dissolution, such as caves and dolines, occurs in the region. In 2019, Curvelo was affected by the subsidence of the land generating large cracks in nearby houses and in the asphalt leaving six families unable to return to their homes. Under this geomorphological context, a different approach is necessary to guide the urbanization of the town, considering its particularity. With a less expensive method this work seeks to delimitate areas that are likely to trigger these phenomena as a way of contributing to territorial ordering, preventing property losses to public authorities. This work uses geological and geophysical data of the area of Curvelo and its surroundings to show regions more favorable to outbreak a land sinking process. This work uses pre-mapped geological data and geophysical surveys of magnetometry, radiometry and electrical methods, to determine different georeferenced classes of influence. This analysis made it possible to regionally characterize geophysical facies and lineaments, which integrated with the use and occupation maps, determine areas suitable for geotechnical problems, and, in a more detailed scale, confirm the presence of cavities through geoelectric surveys. Therefore, maps of potential for deflagration were made based on geological and geophysical analyzes. Integrated in GIS base the analyzed data presented categorized zones of susceptibility to the outbreak of subsidence, as well as made it possible to define the typology of subsidence in the region. Information that helps the management of geological risk areas in the municipality.
\end{abstract}

